\title{
MAKING SPACE FOR 'THE SOCIAL': CONNECTING SOCIOLOGY AND PROFESSIONAL PRACTICES IN URBAN LIGHTING DESIGN
}

Lighting is increasingly recognised as a significant social intervention by both lighting professionals and academic social scientists. However, what counts as 'the social' is diverse and contested, with consequences for what kind of 'social' is performed or invented. Based on a long-term research programme, we argue that collaboration between sociologists and lighting professionals requires negotiating discourses and practices of 'the social'. This paper explores the quality and kinds of spaces made for 'the social' in professional practices and academic collaborations, focusing on two case studies of urban lighting that demonstrate how the space of 'the social' is constrained and impoverished by an institutionalised division between technical and aesthetic lighting. We consider the potential role of sociologists in making more productive spaces for 'the social' in urban design, as part of the central sociological task of 'inventing the social' (Marres, Guggenheim and Wilkie 2018) in the process of studying it.

\section{KEYWORDS}

Light; urban design; inventive sociology; professions; performativity; Actor-network theory

Jo Entwistle, King's

Don Slater, LSE 


\section{INTRODUCTION $^{\mathrm{i}}$}

Light is increasingly being recognized as a significant social material: on the one hand, there is a growing social science of light and lighting that reclaims this material from the purely technical domain (section one); on the other hand, lighting-related professionals increasingly understand their practice as an intervention in social worlds (section two). In other words, a lot of work is being invested to connect light and society, to recognise the centrality of lighting for shaping social space and the centrality of 'the social' in shaping light into the visible forms we experience.

However, actor-network theory and STS tell us that the very idea of 'connecting' light and society causes trouble by assuming there are two already-existing entities - one technical, one social - to be connected, usually by demonstrating the impact of one on the other. This is indeed what our research group is often asked to do by colleagues and collaborators - either to do a 'sociology of...' light and lighting for an academic audience; or to supply lighting professionals with 'evidence-based' findings as to how light impacts bodies, brains or crime rates. That is also to say that the idea of connecting light and society is linked to the separation of lighting-related professions and social sciences into independent practices and knowledges (and to demonstrating 'impact' in 'impact case studies').

Our aim in this article is to explore how different practices (professional and academic) make space for something each calls 'the social' and to explore the shape or quality of the spaces they carve out for it. 'The social', pace Latour, is not a pre-existing thing to be invoked or represented in sociological accounts; and yet it is continuously invoked and performed by actors (including social scientists), with consequences for practice. This also involves a critical or normative concern: from the perspective of our 'social', how do we as academic social scientists relate to the ways in which 'the social' is being invoked and performed in the world of urban lighting? and how can social science professionals involve themselves in the professional configuring of lighting and urban space?

'The social' is not a concept that sociologists are able to simply impose on practitioners. The socialshaped space carved out in professional practices depends on the particular histories, institutions and materials through which they are formed. Hence, making space for the 'the social' needs to be studied as internal to practices (both academic and professional): what material and conceptual forms of association between people and things emerge within the organized flow of professional practices? What is understood by professionals to be 'social' as opposed to technical, spatial, aesthetic, etc? How expansive or constrained, how reflexive or tacit, is 'the social' that lighting people perform? How does it relate to some of the dimensions of 'the social' that sociologists routinely invoke such as social division, inequality, practice, and so on?

The sociological practice from which this paper is written is based on an extended series of collaborations with lighting, design and planning professionals. Our own sense of 'the social' has been produced through our engagement with lighting work as well as through our own prior formation as professional sociologists. In this sense, our work is closely aligned with the movement towards 'inventive' and 'live' methods (Law 2004; Law and Urry 2004; Back and Puwar 2012; Lury and Wakeford 2014; Marres, Guggenheim and Wilkie 2018), which recognizes the extent to which our social scientific 'social' emerges, or can emerge, from forms of participation and engagement, and a commitment to build our own sociology from this recognition. 
Collaboration between social science academics and professional practitioners necessarily involves negotiation, even conflict, over the nature of 'the social', how to study it and what role it is assigned in diverse aspects of a practice (design, implementation, evaluation). While we are not able to simply impose our own 'social' as authoritative or expert (and we have learned to listen more attentively to 'their' various socials), collaboration certainly involves partisanship - we are trying to secure the opportunity for performing 'our' social, we are fighting our corner to show that our social is informed by more rigour, has unrecognized usefulness and is the result of histories of debate and systematic effort. We are concerned with how professional lighting can be sociologically enriched; conversely, in this article we use the term 'sociological impoverishment' to index our sense of how 'the social' may be constrained or marginalized. At the same time, we need to treat the space that sociologists make for 'the social' in the same way as the space made by other professionals, especially since social scientists produce wildly diverse 'socials', without agreement. 'Our social' is only one of many that could be put forward by fellow sociologists, geographers, anthropologists and so on.

This complex negotiation over the nature of 'the social' forms the crux of our argument: post-ANT and inventive methods literature is concerned with acknowledging the performative nature of social knowledges. This continues the long tradition of reflexive sociologies which envision social actors as creative agents who produce their worlds in part through their own social concepts. As a direct consequence, the second order understandings and concepts of social analysts become performative, taken up by social actors in producing their worlds. However, if, like us, you are social researchers trying to collaborate with lighting designers, councils, community groups and other publics, you soon find that performativity is far from the automatic upshot of sociological practice: it is a hard-won achievement. The professionals you work with do indeed have reflexive 'social' concepts, but they are likely not to be yours. Or they are versions so mediated as to be scarcely recognizable as 'the socials' we produce within academic social sciences. Moreover, as we indicate later, professional invocation of 'the social' can simply be a way of commercially branding a design practice, or securing Bourdieuan field advantages in the form of status, such that 'the social' is a signifier that no one feels particularly obliged to specify at all. Far from needing merely to recognize and take responsibility for the performativity of our social science, we experience continuous performance anxiety as we seek to get our version of 'the social' enacted.

Making space for 'the social' - and the 'right' kind of space, the space we seek to promote from our academic standpoint - is consequently a fraught negotiation rather than an automatic performativity. Section three explores the making of social-shaped spaces in professional lighting practices through two case studies. Both revolve around what we take to be a fundamental discursive split within lighting - that between technical and aesthetic framings of light; the case studies therefore consider how 'the social' has been shaped and - we argue - 'impoverished' by this division. In our concluding section we return to the idea of inventive methods and the ways in which sociological practice is positioned by the different spaces made for 'the social'.

\section{METHODOLOGICAL BACKGROUND}

The initial aim of our research programme was to open up light as a neglected empirical object to sociological scrutiny. Our focus was on the dynamics of lighting practices within public realm lighting and how they enacted social space. Beginning with ethnographic observation of lighting design practices, we were then actively encouraged by the professionals we encountered to participate as consultants, in the construction of 'the social' from our sociological perspective. 
This dual role - as sociologists of and within these lighting processes - has continued over many collaborative projects. These include the two case studies, below, in which we conducted social research as part of design processes, while also studying them as ethnographers. Additional projects (see www.configuringlight.org) include 'Smart Nighttime Design' (a two year collaboration in Cartagena, Colombia with designers from Arup and additional spatial and urban analysts); research and workshops with the Mairie de Paris to light the Place des Fetes; and 'Achieving Publicness in Elephant Park' - a (so far) three-year study with extensive access to the developer, LendLease, and its landscape and lighting design. Other forms of collaboration cross the academic/professional divide have included a workshop series on 'light and inequality' to bring together policy makers and academics (Sloane, Slater and Entwistle 2016); and seven 'Social research in design' workshops in which designers study specific sites for 3-5 days, integrating social research into their production of design strategies (Slater, Bordonaro and Entwistle 2018).

Methodological details supporting our two case studies follow below. Methodologically, however, the paper draws on all these multiple engagements and the long-term dialogue between our sociological 'social' and their professional 'social'. Importantly, while these collaborations are evidence that making space for the social has been welcome, we also encountered fundamental institutional divisions which served to divide and constrain the space of 'the social'.

\section{SOCIAL STUDIES OF LIGHT AND LIGHTING}

While social sciences have been profoundly transformed by making space for 'the material', proper analytical symmetry in investigating materials like light requires more movement in the opposite direction, to return to the concepts of 'the social' that are performed in the professional configuration of materials. The socialness of light takes at least three major forms that open it up to a sociological gaze. Firstly, lighting materially shapes spaces of social interaction. When lighting professionals cast light on a social scene, they perform complex socio-technical assemblages that produce social spaces, with implications for how spaces are populated, used, and experienced. Secondly, light is a material that is configured through socio-culturally specific technologies, practices, regulations, cultural forms, values and knowledges. This is significant today, with intensive technological and institutional change - LED, control systems, 'smart' and big data - routinely challenging understandings of how light is to be materially configured. Thirdly, lighting is at the centre of multiplying social issues and controversies - e.g., light pollution, circadian rhythms, economic and environmental sustainability, crime and security, etc. - through which this material is re-imagined and used to articulate new relations between social, technical and 'natural' processes, and through which concerned publics are assembled, and 'material participation' and 'material politics' enacted (Entwistle and Slater under review).

Moreover, all three points of sociological interest involve interdisciplinary negotiation (Barry and Born 2014), e.g., the current topicality of circadian rhythms and related health claims has shifted lighting studies, professions and industries towards bio-sciences and causal accounts of the impact of light frequencies on bodies and behaviours. Hence, 'human-centred lighting' is increasingly largely understood by professionals as a biological or behavioural matter rather than one of social patterns and practices (see section three). 
All three points both highlight the 'socialness' of light and render it contestable. However, light received little social science attention until the past decade. Previously, academic lighting research was split, like the professional discourses discussed in section three, between technical literatures that sought to measure the impact of light on behaviours; and an aesthetic framing of lighting within design history, visual representation and performance. One exception to this absence was Schivelbusch's (1995 [1983]) genealogy of lighting in Disenchanted Night, where lighting technologies appeared as emergent actors in a fully social-technical drama of modernity.

How do the new literatures on light position the questions we are exploring? Drawing initially on material culture studies in anthropology, new social studies of light (see Bille and Sorenson (2007)) focus on how specific ways of doing light constitute 'light cultures' (Bille 2013: 11, 2015: 2) that recursively reproduce specific social forms - e.g., hygge (often translated as 'cosiness') is an organizing logic of Danish domesticity and of national branding. Ethnographic attention is directed not only at the situational reproduction of lit social spaces (homes, streets and offices) but also to wider social reproduction. For example, people's normative sense of a properly lit home connects to the consumption and regulatory structures under-pinning energy use (Bille 2013; Pink and Leder Mackley 2014; Shove and Spurling 2014; Genus and Jensen 2017). However, this literature has not extended to how lighting professionals perform light cultures within their own practices.

Lighting studies converge with concepts of affect and atmosphere (Anderson 2009; Bille, Bjerregaard and Sørensen 2015; Ingold 2016; Edensor 2017), drawing on Böhme's (2017) phenomenological analysis of 'atmosphere' as the experiential structure of embodied spatial feeling. As a constituent of atmosphere, light is a core affective material that contributes to 'tuning' the embodied feeling of a space. While atmosphere opens a crucial dimension of space, it tends to focus attention on spectacular forms (light festivals, light art and tourist sites) separated from the mundane stuff (streetlights, bollards, retail signage) constituting the material fabric of streets (Edensor and Millington 2009; Edensor 2017). There are notable exceptions to this within cultural geography. Shaw (2014: 2228) examines how lighting engineers' knowledge frames decisions and choices over lighting technologies and policy and argues there is a 'significant gap' in terms of how this connects to the 'tacit and experiential ways in which people engage with infrastructure on a day-to-day basis'. In sympathy with this view, Ebbensgaard (2016) analyses how street lighting is experienced within the everyday routinized practices of older residents in the London Borough of Newham, which he argues are consequential to Newham Council's policy and practical implementation of its new lighting plan.

What remains under-researched are the ways in which atmospheres connect to wider circuits of professional lighting in manufacturing, design and regulation. Yet terms like atmosphere and ambience are shared with lighting professionals whose use of these concepts needs to be understood in relation to their practical construction of 'the social'. As explored below, within lighting professions, atmosphere is regarded as an aesthetic property of privileged social spaces (heritage and commercial centres) while other spaces, such as housing estates, are not sufficiently valued to merit an atmosphere. Indeed, little empirical attention has been paid to atmosphere as the outcome of design practices. Significantly, although Bohme (2017) discusses atmospheres as the 'staging' of scenes by theatrical directors, designers and advertisers, he characterizes this aesthetic labour not in terms of empirically observed professional practices but the manipulative aestheticization produced within consumer capitalism, largely based on dated critical theory. 
We might instead turn to the currently burgeoning literature on design professions for academic discussion of the construction of 'the social' within professional design practices. There is in fact a long history of literatures that critically theorize designers' relationships to 'the social', from William Morris's activist cultural politics to Bauhaus engagements with technological modernity. The critique of 'normal' design, which appears as socially disengaged and irresponsible (either pure craftsmanship or technocratic functionality) is exemplified by Papanek (1985 [1971]) for whom 'the social' is both the context for and the goal of design work. However, he argues that most designers occupy a purely technocratic position in industrial capitalist processes, blinding them to social values and ends and evading social responsibility and social relevance (Clarke 2013). The problem however is that in these accounts 'the social' doesn't play a role in design practice (except in the narrow sense of identifying given social 'needs'); on the contrary, it is construed as 'out there', as an already existent entity with which designers must reconnect. Similarly in the urban planning of Jan Gehl (2011 [1980]), 'the social' is to be measured, observed and incorporated into better design work to uncover 'life between buildings', but again it is an 'out there' that planners must be made to connect with. Clearly this fails to recognise the designer's own performativity as a producer of 'the social'.

More promising is the broad tradition of user studies, particularly within STS and ANT, which is concerned with how end users and uses are internalised within designed objects (scripting, programming, etc) and how this contributes to the distribution and delegation of 'the social' across production and consumption, and between objects and users (Akrich 1992; Latour 1992; Oudshoorn and Pinch 2003; Ivory 2013). Focus on the narrative construction of anticipated users and social futures, under the banners of sociology of expectations and speculative method, have generated studies of performance of 'the social' (Wilkie and Michael 2009) as well as methodologies for connecting social and design invention (Dunne and Raby 2013; Wilkie, Savransky and Rosengarten 2017). Finally, and closest to our arguments, are explorations of design cultures (Cuff 1992, c1991; Kimbell 2011; Farias and Wilkie 2015) that focus on design as situated practices along the lines of laboratory studies, and which rigorously treat design work as performative, with close attention to the ways in which concepts are formulated within design processes.

Finally, there is literature on participatory and co-design: conceptualising how design connects to 'society' requires ontologies of what this society is made of (stakeholders, power, expertise, etc). While user involvement in design has become mainstream in many product design areas, it is marginal in the professional worlds of lighting and urban design. More common - indeed often required by planning departments - is the formalistic invocation of 'the social' through consultations (Rydin 2007). The consultation is a device ostensibly to make 'the social' speak, to represent itself in an actionable form. Apart from the limited public that actually speaks, consultations do not generally acknowledge their own performativity. This critique is better articulated in literatures from development studies (Green 2000; Riles 2000; Slater 2013): professional networks conjure up an 'outside' that they can represent, 'a society' in whose name they can then speak. The same point can be made about 'smart' technologies and big data within design and planning:there is an assumption that 'the social' is that which automatically represents itself through mechanisms such as the algorithm and the sensor.

\section{MAPPING 'THE SOCIAL' IN LIGHTING DESIGN}

\section{THE SOCIOLOGICAL 'SOCIAL' MEETS THE PROFESSIONAL 'SOCIAL'}


Over the same period that academics discovered lighting, lighting-related professions have foregrounded 'the social'. Firstly, a social turn within lighting and public realm design has been signalled by the rise of urban lighting masterplanning, starting with Lyon's 1987 plan and gathering momentum from the late 1990s. Masterplanning aims at a coherent city-wide lighting strategy that fits within politically agreed development plans (see Entwistle and Slater under review). The lighting masterplan is concerned with functional needs (traffic and pedestrian safety, zoning, etc) and aesthetic value, including a coherent urban visual identity. Masterplans tend to centre on urban typologies that include social forms: what kinds of streets, buildings and public spaces with what kinds of functions? However, the tendency is to equate 'coherence' with purely technical standards or the top-down imposition of design schemes (Kohler 2014; Lee 2014).

Secondly, lighting masterplanning, particularly from the 1990s, connected to a wider movement towards 'social lighting', via Roger Narboni (2004), Brandi (Brandi and Geissmar-Brandi 2007) and Louis Clair (2003). Further, lighting activists such as the Social Light Movement and Lumières Sans Frontières championed 'social lighting' to focus on lighting as community-engaged social intervention within urban areas (poor, marginal, 'ethnic') outside high-status city centres, while professional bodies such as LUCI have worked since 2001 to help cities shift light planning beyond the technical to a wider remit of 'quality of life' for multi-cultural populations.

Finally, lighting design is a marginalised profession, subordinated to more powerful professions such as architecture; one strategy for increasing professional status within the field has been to make claims to 'human' or social knowledges, and to articulate design philosophies that integrate the technical, aesthetic, social and spatial. Two examples from long-term Configuring Light collaborators: Speirs+Major explicitly theorize their practice in terms of Kevin Lynch's (1960 [1975]) spatial analysis in which lighting serves to make more legible an 'image of the city' that connects urban morphology to social practices (cf Major 2015). Similarly, Leni Schwendinger, previously with Arup's urban lighting group, contributed an approach to 'night-time design' in which lighting becomes part of orchestrating all the material elements of urban social space after dark (Arup 2015).

Our ongoing collaborative work with lighting designers has depended on this professional 'social turn' establishing a convergence between lighting practice and sociological research. For a lighting designer to light a public space involves understanding what people are doing, how they are moving at different times, for what reasons, what environmental features they value, need and use and how they experience the identity and ambience of a space. Lighting professionals act upon these features at mundane levels, often governed by lighting standards that formalise relationships between light and social practice in great detail. For example, lighting designers talk about task lighting, wayfinding, narratives and scenes, each relating lighting to mundane social practices.

However, while lighting professionals are naturally engaged with social practices, our interviews and observations show that they routinely feel on shaky ground, without the methods, concepts or data that should provide reliable and actionable social knowledge. This need is not met by standard statistical measures (e.g., footfall or demographics) which offer limited connection to practices or their mediation through different social groups. For many lighting designers, 'social research' means field visits, anecdotes and very selective voices from community consultations. Thus, while lighting professionals we work with are engaged with social life and aware of the role light plays in supporting social practices, mobilities, meanings, identities, they tell us they lack a systematic social knowledge. 
Our collaborations with lighting professionals have connected with their need for 'social rationales' for design decisions: we are invited to supply and represent 'the social' by providing social research methods to go alongside the aesthetic, technical, political, financial and other knowledges they employ (Slater, Bordonaro and Entwistle 2018).

We can summarise this convergence between 'our' social and 'theirs' in two points that have formed the basis of our various collaborations: First, making space for 'the social' means engaging lighting as a material intervention into diverse spatial social practices within differentiated groups of people as they are collectively organised, focusing on social differences, rather than disaggregated 'individuals' or aggregated 'communities'. Second, studying 'the social' in lighting means deploying a range of (often bespoke) research methods that rigorously map this complex socio-technical world and open it to challenge and creative response. What should emerge is an understanding of social space that not only acknowledges but in various senses activates the diverse people and practices that make up the life of a street, park, or housing estate one is trying to light. Most significant in our own collaborations has been the use of sociological concepts and methods to engage with the embodied presence of actual stakeholders rather than with the virtual or projected people that emerge from formal consultations, statistics or - as often as not - the unchallenged anecdotal impressions of designers and planners. The fluid complexity of 'the social' as derived from social sciences above all stands for its potential to open up design processes to challenge through empirical engagements with realities that it may not even have been aware of.

\section{THE PROFESSIONAL 'SOCIAL' AS MEDIATION}

Our collaborations evidence how our own social science version of 'the social' resonates with needs of professional practice. However, we need to qualify this neat picture. We have generally worked with leading edge design practices whose status is bound up with engaging the social character of lighting; public realm lighting itself - a vividly social intervention as compared to lighting hotels or restaurants - involves high status but low profit commissions not all design practices can afford.

Lighting design is more often what we will describe as 'sociologically impoverished', routinely applying technical standards, or - occasionally - providing socially arbitrary aesthetic embellishment.

Moreover, while we might claim a natural affinity between our 'social' and that of lighting designers a panoply of other actors (councils, planners, developers, consultants, marketing departments, engineers, manufacturers, technical standards, LED technologies, control systems) are also involved in producing, mediating and enforcing constructions of 'the social' to which lighting is to be connected. These diverse 'socials' can be in considerable tension with our sense of 'the social'. Three competing 'socials' are particularly worth noting here. All three have been identified through our research experiences, trade publications and professional relationships accumulated across the diverse research involvements indicated under 'Methodological background', above. We have also suggested some significant examples.

First, 'the social' is sometimes reduced to social problems: while sociology and most other social disciplines regard all social settings as 'social', for institutional collaborators only problematic or marginal spaces count as 'social'. By the same token, light is sometimes seen as a social matter only when it aligns with headline issues and matters of 'social concern': e.g., crime, light pollution, sustainability, health impacts. Similarly, 'the social' is frequently reserved for types of places, residential as opposed to commercial zones, or seen as a 'cultural' matter only when light shines on 
iconic, branded or heritage sites. Making space for 'the social' has often meant generalising 'the social' to all spaces.

Second, 'human-centred' design has become an important rallying point (and marketing strategy) for academics, designers, manufacturers and municipalities: lighting should be focused on 'the human', defined both as universal ('people') and as opposed to objects (particularly cars). This frames lighting within psychology or biology, and assumes collectivities (people, humans, 'the community'), both occluding the idea of 'the social' as a complexity of associations that differentiates what light shines on and that mediates the impact of lighting on bodies or minds.

Third, 'the social' is often operationalised by deploying devices through which 'it' can automatically represent itself, such as public consultations, participatory design, social media and 'big data'. 'Smart' lighting, for example, promises to automate the production of 'the social' by translating population movements into real-time data flows. Whatever these devices produce is 'the social' to which the lighting professional is accountable.

From the standpoint of our engagement with professional lighting, as mapped out above, these understandings reduce or impoverish 'the social'. In the following section, we explore this reduction empirically through two case studies.

\section{THE TECHNICAL AND THE AESTHETIC: THE PROFESSION OF LIGHTING CITIES}

In this section we present two case studies of professional urban lighting in order to explore the space that is made for 'the social'; and to explain why - as academic social researchers - we felt that space to be impoverished. Both cases hinge on what we take to be a fundamental distinction between technical and aesthetic framings of light, an institutionalized dichotomy that works to limit the space of 'the social'. The distinction itself therefore needs some explanation in advance of the empirical examples. On the one hand, lighting is frequently framed as a technical practice, a bundle of measurable properties deployed to secure specific social functions such as task lighting or safety. On the other hand, lighting can be framed as aesthetic practice, the production of visual spectacle (such as now-ubiquitous lighting festivals) or of specific spaces coded as aesthetic - beautiful, photogenic and atmospheric - such as 'heritage' districts and high-value commercial centres.

This distinction was part of the formation of urban lighting as it emerged in early modern Europe. Initially, lighting served as the functional delivery of public order and pedestrian safety from crime and vehicular risk by private lighting firms and municipal regulation (Schivelbusch 1995 [1983]). Prior to municipal street lighting, cities after sundown were deemed dangerous, with order to be maintained by curfew (Beaumont 2015). From the introduction of rudimentary public lighting in the 1680s in Europe (following the requirement for private houses to light lanterns at night), lighting was tied to cost efficient provision up to standards deemed technically to discharge public obligations to secure public order.

At the same time, the newly lit city was also an aesthetic production, a transformation of urban night into dramatic spectacle. The modern city as a luminous experience is central to a wider modernism in which lighting, municipal and commercial, constitutes the spectacle of modernity itself (McQuire 2005; Isenstadt, Dietrich Neumann and Petty 2015). This aestheticization includes spectacular events that used advanced lighting to perform celebrations of modern industrial energy, such as world 
expositions, as well as the visual by-products of that modernity - advertising, streetlights, brilliant skylines. Beaumont (2015) traces this back to the eighteenth century: even the weak lamps of the link boy enlightened the urban night to produce a new urban drama: 'nightlife'.

Urban lighting therefore splits between functional responsibilities discharged by cities and production of spectacle by aestheticizing agents. Petty $(2007,2016)$ shows that this distinction was central in the professionalisation of lighting design in the US from the 1900s: a central issue was whether professional bodies should organize as 'illuminating engineers' or 'lighting designers'. This distinction is often institutionalised in municipal arrangements: for example, in Brisbane, Australia, street lighting comes under Queensland's state responsibility for transport safety, while there is a separate city-level programme for 'creative' and event lighting. In the Derby case, below, the lighting strategy produced by urban designers was undermined by another department mounting event lighting that they were never told about.

\section{TWO CASE STUDIES}

Our two case studies involved making space for 'the social' within this pervasive distinction by collaboration between social research and urban design professionals. We worked both as academic ethnographers and as contracted researchers. In Whitecross, a Peabody housing estate in inner London, we were invited by the Peabody 'Improve' team to expand an earlier 'social research in design' workshop we carried out there in October 2014. This workshop - in which 25 designers developed lighting strategies based on conducting their own social research - significantly challenged Peabody's view of lighting as a matter of maintenance and safety. During the five-day workshop, designers encountered users' understandings of their social spaces, challenging their own spatial understandings: e.g., one design team discovered through interviews that the side of a housing block that they identified as the front entrance - from estate plans - was regarded by most residents as the back of the building. Following the workshop's success, Peabody invited us to do further social research, develop a public realm lighting scheme and produce guidelines for integrating social research into estate design. This research comprised interviews with Whitecross residents and Peabody staff, and participation in design meetings.

In Derby in 2014, we were given access to the lighting masterplanning process under the Council's Regeneration team, working with the lighting design practice, Speirs+Major. We conducted research integrated into the design process (studying users and stakeholders of the nocturnal city centre and mapping their pathways); at the same time, we interviewed and observed Derby council and S+M staff, thus allowing us to study the masterplanning process itself.

\section{WHITECROSS}

Whitecross is a social housing estate in central London run by Peabody Trust, a socially-oriented organization, well-connected to residents. However, before our intervention, light was regarded as a technical matter deployed solely for safety and security at minimum cost. Not unusually, 'safety' and 'security' were trump cards played by both Peabody and vocal residents to veto design decisions intended to further other social values such as conviviality, interconnection or atmosphere. For example, invoking 'safety' meant light should be bright to prevent falls or accidents, while quality light with good colour rendering was deemed inappropriate because it might enable junkies to locate their veins. Similarly, lighting a green space or providing benches might attract undesirables. 
This reduction of lit social scenes to safety and security fits with wider technical/aesthetic divisions played out at a city scale and which supports a politics of design inequality: social housing estates are framed as inherently problematic spaces of potential public disorder, crime and danger and therefore lit largely within regulatory and disciplinary logics. Foucauldian 'panopticism' is certainly an apt reference: the standard result is 'prison-yard lighting' - over-bright, uniform lighting from high masts to achieve maximum visibility and surveillance - that links technical lighting with crime reduction and increased perception of safety (on little consistent evidence). Such lighting codes these estates in terms of social inequalities that it spectacularly reproduces: contrast this functional coding of social housing with upmarket neighbourhoods and city centres lit for atmospheric quality, heritage or entertainment. The latter are accorded a right to be aesthetic, denied to estates, and indeed an aesthetic role in urban development plans. This technical/aesthetic split is therefore instrumental in differentially valuing social spaces and reproducing urban spatial inequalities (Sloane, Slater and Entwistle 2016); social inequality is reproduced through an impoverishment of 'the social' as professionally performed through the technical/aesthetic division.

Once identified with public order functions, a technical logic dominates all aspects of lighting social housing. Within estate management, spaces were administratively differentiated according to functional rather than social logics. For example, internal and external lighting - tied to different technical issues and standards - were located in separate departments and budgets, preventing integrated estate lighting despite the fact that light continuously spilled across spaces that were socially connected. Specifically, some housing blocks had external walkways leading from stair wells across front doors, making them simultaneously external access routes and private spaces. These walkways were lit by 'bulkhead' lights, producing extremely bright, poor quality light, instantly recognisable as 'council house' lighting, and justified in terms of safety and security. Some tenants taped black bin liners over their windows so they could sleep (perversely losing essential sunlight during the daytime). Yet both Peabody and resident groups assumed that lower light levels would be unacceptable to tenants as unsafe.

Standardized brightness levels depended on social classification of the balconies. Peabody had chosen to define them as internal corridors, requiring lighting to 100-150 lux. They could equally have been defined as exterior passageways (5-30 lux) or even external pedestrian spaces (2 lux). Given that 1 lux is the light cast by a full moon on a cloudless night, and 200 lux is the lighting standard set for internal public gathering spaces, there is a huge potential technical variation based on unexamined, undiscussed social categorizations. In fact, tenants' classifications were also ambiguous: in doorstep conversations, these spaces were regarded as private entrances, and complained about the brightness; in public consultations, however, vocal residents defined these spaces exclusively as public safety matters. Peabody understandably resolved this ambiguity in favour of technical safety standards rather than opening up for discussion these more complex social understandings of specific spaces which would also destabilise practical assumptions (widely shared by institutions like the police) that brightness secures safety. Moreover, this technical response allowed Peabody's duty of care to be discharged by ensuring 'acceptable standards' were observed.

This problem of overly bright balconies was not due to Peabody's lack of social concern but the reduction of 'the social' to technical standards, which we take to be an important case of sociological impoverishment. Standards (Bowker and Leigh Star 2000) connect light and social worlds through typifications of social settings and social actors, such that normative levels and qualities of light can be 
applied, and designers and their clients can be seen to discharge their duty of care. Lighting designers themselves are generally ambivalent about standards. On the one hand, typification of the social to identify technical 'best practice' both articulates duty of care, and also rationalises work processes by reducing ambiguity. On the other hand, however, designers are routinely aware that they are always designing for particular people and practices and can rarely just apply the 'right' number; knowing which number to apply is a matter of social interpretation, instinct, experience, knowledge. As Kevin Lynch (1984: 152) put it: 'Much of the bread and butter of city design and management deals with fit [between 'place and action']...', with 'fit' reduced to a standardized 'quantitative adequacy', that ignores 'the qualitative basis of these numbers'. This 'fit' by-passes social understandings of whether there is an 'adequate' fit for different actors: '[S]tandards are developed for these typical settings and the analysis of fit becomes a matching against standards.' (158)

What did 'making space for the social' mean in this story? It meant moving from ways of thinking about lighting that standardized 'the social', preventing public interpretation of social spaces. This meant challenging the coding of Whitecross exclusively as a safety concern to be dealt with technocratically: for example, at one point Whitecross was proclaimed the first social housing estate to get designed lighting. The workshops acted to introduce alternative social values beyond safety and security, while a 'Guerrilla' lighting event held on the estate helped to introduce 'aesthetic' values as an experience of social transformation rather than embellishment or place marketing. Our collaboration involved moving debate within Peabody/Whitecross from the application of standards to a public discussion of social practices, meanings and values.

\section{DERBY}

In 2013 Derby city council's regeneration team commissioned a lighting masterplan as part of their development framework (Entwistle, Slater and Sloane 2015). Configuring Light obtained access to this process through the lighting designers tasked with the masterplan, Speirs+Major $(S+M)$, and, with the support of Derby Council's 'regen(eration) team', we were invited to contribute social research to the masterplanning process.

The masterplanning commission was itself part of the regen team's wider struggle to open up a political space between technical and aesthetic discourses within city planning (Entwistle and Slater under review). Derby had recently been locked into a 25-year private finance initiative (PFI) with engineering firm Balfour Beatty (BB), within a context of swingeing budget cuts. The PFI relied on a purely functional specification of lighting that mirrored the Whitecross situation: the contractual concern was to meet duty of care obligations for safe streets by meeting lighting standards for parameters such as brightness, colour rendering index, mounting height and uniformity. Concerns of heritage, atmosphere, event lighting, environmental issues and innovation were additional or residual. BB could rapidly install a standardized, large scale system in the first two years and collect on this investment from the council for the next 23 years.

This neo-liberal arrangement was enabled by an impoverished version of 'the social': by reducing lighting to technical standards, functions and cost it could be contracted out to an engineering firm with no design involvement. The Derby regeneration team, by contrast, was led by urban planners who shared a commitment to 'design' as a holistic approach that could treat public space as lived social space. To the regen team, the BB PFI symbolized all that was wrong in urban planning, not just lighting: it meant the privatization of lit urban space and, as the lead lighting designer put it, produced 
lighting that 'was just fucking horrific... [BB engineers] just sent lighting calculations and they're lighting everything to major highway intersections or junction light standards.' (interview) 'Prison yard lighting', justified by safety standards, produced profoundly uncomfortable spaces because the over-lighting obliterated social meaning and, by contrast, created dark, threatening adjacent streets. This was most evident in the low-value commercial area in Derby city centre, St Peter's, dominated by pound shops and betting shops. As with Whitecross, functional lighting defined social spaces solely as incipient problem spaces, coded for inequality: at the other end of the city centre was the heritage 'Cathedral Quarter' which retained picturesque buildings, independent shops, cafes and bars and which was lit with faux heritage lights, mounted at human scale, with warm tones, all designed to establish atmosphere.

The technical logic of the PFI left the regen team little room to treat lighting as social fabric; their only room for manoeuvre was mapped out by the aesthetic: Firstly, the PFI contract contained clauses that required BB to meet city demands for 'creative' and 'innovative' lighting - lighting related to events, atmosphere and entertainment - plus provision in the event of technical changes (this agreement was implemented, irrevocably, just a couple of years before the LED revolution overtook cities globally). Although aesthetics was contractually restricted to spectacular and event lighting (festivals, light shows, entertainment venues) and not extendable to mundane street lighting, the regeneration team could leverage these clauses in their initial attempts to redesign the city. The resulting 'social' however was a tourist-driven entertainment city, rather than a diversified landscape of mundane practices. In this context, the hiring of Speirs+Major to do a masterplan was a strategic move from both functional lighting and (aesthetic) event lighting to a full implementation of urban design.

There was, however, a second aesthetically defined counterpoint to the technicality of the PFI: placemarketing to attract inward investment and tourism, as championed by Marketing Derby. As in Julier's (2005) discussion of cultural regeneration in Hull, Derby council aimed to mobilise a new vision of the city. Like Hull, Derby suffered from 'lack of aspiration and confidence' (Julier 2005: 883) that was widely discussed by stakeholders. Marketing Derby addressed this by promoting iconicity and semiotic (re)coding of the city through lighting. This use of light fit within the regen team's strategy but was also at odds with it: it focused primarily on consumable aesthetic images of the city, not uses and practices within its everyday life. It can be expressed in terms of the difference between placemarketing aimed at generating investment in the city from 'outsiders' and place-making aimed at city spaces that work for everyday users (Chang and Huang 2008). The regen team's masterplan commission - and their enrolment of us as sociologists - was step towards the latter.

Marketing Derby's interest in lighting, by contrast, was semiotic: to create aesthetic images that coded the city as desirable to investors. Significantly, at the time of our fieldwork almost all images in 'Marketing Derby' publicity material were romantically lit night photographs and films for 'invest in Derby' (http://www.marketingderby.co.uk/invest-in-derby/) As the marketing director straightforwardly put it, 'we will use light to try to make the city more attractive...to sell the city to visitors'.

Place-marketing approaches share with technical lighting discourses a disconnection from 'the social' as practices lived and experienced by determinate actors. One particularly striking image in the Marketing Derby brochure showed a lit bridge traversed by a lone woman with the Derby skyline and cathedral in the distance. She is a semiotic invention, not least because residents know (and our 
research showed) there is little reason, particularly for women, to go to the river at night, a lonely place with negligible footfall. It was not a recognised pathway into or out of the city centre, except for a few (mostly male) residents on their way to a real ale scene across the river. Here lighting matters only in producing a city-to-be-photographed, presented in representation to potential investors. Such aesthetic lighting, like technical standards, comprises generic social codifications. The river image is a cliché of city branding. As Lee (2014) argues, the emergence of the skyline as a favoured perspective in nineteenth-century New York has to do with how people began to approach the city by rail and road. This imagery views the city from a distance, a memorably photogenic perspective. Pretty images of night-time Derby, seen from a distance, present an alternative image to the unattractive functional lights inflicted on actual streets, but have nothing to do with the way people experience the city at street level, with its social rhythms and flows. One Marketing Derby person's comments exemplified this socially unanchored semiotics:

I imagine that if you were to take the development map out, there are things that are lit up that are beautiful, and there's things that could be lit up that are ugly, where the lighting can beautify that bridge for example. ... I've seen it in France where lighting can make something quite ugly look quite presentable. You've got massive opportunities in the city... it's a blank canvas why doesn't somebody please do something with it? (interview transcript)

The regen team, fighting for a socially informed urban design, were very clear about the problem with this aesthetic approach and the assumption that Derby was a 'blank canvas' rather than a social world: 'aesthetics' can appear "empty"; aesthetics is important, but we often try and steer people away from it' (interview with urban designer). She explicitly distinguished 'aesthetics' from 'atmosphere' which she understood to reference the ways in which embodied people experience and use a space.

Despite this semiotic emptiness, Marketing Derby actually made a good case for a version of 'the social' not too far away from the regen team's: Derby's city centre was largely deserted by night, mainly because residents live in outlying areas and increasingly seek their night-time entertainments in neighbouring cities:

so, our strategy is very simply [to] get the middle classes to ... come here. And the only reason they will come here is $A$ if there is something for them to do, ..., and B if they come into town it's actually quite pleasant and it feels nice, it feels like the sort of place you want to be... So that's where it [lighting] fits in the regeneration strategy for me, I think it can add value to this turn around. (interview)

Whereas the PFI aimed to secure minimum technical standards cheaply, and Marketing Derby to sell the city centre through beautification, the regen team championed urban design as a commitment to building social space, championing urban design as a holistic approach to urban social activation. The enrolment of both S+M (famous for combining social and spatial analysis) and Configuring Light (as LSE sociologists) was part of a wider strategy of network-building by the regen team: the team leader brought in figures as diverse as police, digital enterprise experts, entertainment and festival organizers and housing developers. Lighting served as a focus, important in its own right but also offering symbolic and public demonstration of potential transformations of everyday urban life. Our role as sociologists in this process was to represent or speak for 'the social' by producing knowledge 
of 'it' (identifying stakeholders, nocturnal pathways, moving the agenda beyond safety, and literally speaking up for 'the social' in meetings, documents, informal conversations and work processes) for the regen team to leverage political, financial and material space for a more vital, attractive 'social' in Derby. (Entwistle and Slater under review)

\section{CONCLUDING DISCUSSION}

We have traced diverse openings for 'the social' in both academic and professional discourses on lighting and explored some difficulties involved in making a space for 'the social'. We began by arguing that it is crucial to look into the institutional histories and processes that situate 'the social' in professional practices, however defined. Lighting served as a strategic example of how different social-shaped spaces are made, and how institutionalised distinctions - between the technical and aesthetic in our case - can produce a sociologically impoverished space for 'the social'. The technical modality reduces 'the social' to generic situations and actors to whom standardised measures are applied; the aesthetic modality reduces 'the social' to representations - photographable events and place-branding iconicity. These modalities are politically significant: in Whitecross, this distinction enforced a politics of design inequality which split 'the social' between spaces lit for safety and spaces valued for their aesthetic qualities, while Derby was effectively divided in two: a functionally-defined infrastructure sold to private capital; and a place-marketing aesthetic image sold off to incoming investors.

Our collaborations with lighting professionals in both cases were partisan: we are trying to carve out space for what we recognise as our 'sociological social' (though it could equally be a geographical or anthropological one), one which seems to resonate with some basic parameters of lighting practice, and which (some) lighting professionals welcome in their design work but which they also mediate in ways that we as sociologists may find problematic. This returns us to the points made in the Introduction: our whole research programme has aimed to be performative and inventive (to have 'impact'). However, the claim to performativity - that social sciences play a strong role in constituting the phenomena that they then represent - is always an empirical claim: in any particular case, how far were they (we) actually able to be performative? And through what social mediations? Under what constraints and conditions? We have openly presented these issues from our own standpoint as professional sociologists: we advocate our own space for 'the social'. Making social life is 'performative, reflexive and material' (Marres, Guggenheim and Wilkie 2018: 19) but this does not mean that social science concepts are what other social actors perform, or that they automatically perform our sociological social.

Perhaps this involves a return to an earlier ANT of translations and enrolments: what gets to be a mediator, and what role does it play? This equally applies to sociology's field position: which sociologies (or other disciplines) are actually achieving performativity, or allowed to invent anything? In lighting, we are competing with, for example, statistical sociologies of footfall measurements, economic cost-benefit analysis and psychologies of perception and cognition. Perhaps 'the social' is best treated as one of those boundary objects passed between communities of practice that only just retain a stable identity, and only through constant negotiation or strategic ambiguity. (Star and Griesemar 1989) 
We would therefore want to see our practice in relation to debates on 'inventive' methods. Our collaborations, often deploying conventional sociological methods, are engagements in which we work with practitioners in both inventing social spaces and inventing the space of 'the social' itself. Social science research, on this basis, can contribute concepts that enter into the world such that 'theories and methods are protocols for modes of questioning or interacting which also produce realities' (Law \& Urry 2004: 395). The move from performative to inventive sociology (Marres, Guggenheim and Wilkie 2018: 34) argues that it must and should do so: recognising performativity positively demands that we move on to invention, to finding new ways of doing sociology in which we treat intervention as a central sociological task, both politically and methodologically: quite simply, if 'the social' is a performative concept, then part of our job is to ask what kind of world we are trying to invent, and how. What we hope to have demonstrated through the case of lighting is the complexity of negotiations, institutional arrangements and conceptual mediations over the very space of 'the social' that we must enter into in order to be inventive.

\section{REFERENCES}

Akrich, M. 1992 'The de-scription of technical objects' in W.E. Bijker and J. Law (eds.) Shaping technology/building society: Studies in Sociotechnical change, Cambridge, MA: MIT Press.

Anderson, B. 2009 'Affective atmospheres.' Emotion, Space and Society 2(2): 77-81.

Arup. 2015 'Nighttime Design: Principles and methods.' available at http://www.configuringlight.org/activity/lighting-research-in-cartagena/.

Back, L. and Puwar, N. 2012 Live methods, Malden, MA: Wiley-Blackwell.

Barry, A. and Born, G. 2014 Interdisciplinarity: Reconfigurations of the social and natural sciences, London: Routledge.

Beaumont, M. 2015 Nightwalking: A nocturnal history of London Chaucer to Dickens, London: Verso.

Bille, M. 2013 'Luminous atmospheres.' Ambiances on line http://ambiances.revues.org/376.

Bille, M. 2015 'Lighting up cosy atmospheres in Denmark.' Emotion, Space and Society 15: 56-63.

Bille, M., Bjerregaard, P. and Sørensen, T.F. 2015 'Staging atmospheres: Materiality, culture, and the texture of the in-between.' Emotion, Space and Society 15: 31-38.

Bille, M. and Sorensen, T.F. 2007 'An Anthropology of Luminosity: The Agency of Light.' Journal of Material Culture 12(3): 263-284.

Böhme, G. 2017 Atmospheric Architectures: The aesthetics of felt spaces, London: Bloomsbury Academic.

Bowker, G.C. and Leigh Star, S. 2000 Sorting Things Out: Classification and its Consequences, Cambridge, MA: MIT Press.

Brandi, U. and Geissmar-Brandi, C. 2007 Light for Cities: Light Planning in the Urban Space. A Handbook, Basel: Birkhäuser. 
Chang, T. and Huang, S. 2008 'Geographies of everywhere and nowhere: Place-(un)making in a world city.' International Development Planning Review 30(3): 227-247.

Clair, L. 2003 Architectures de lumières, Paris: Fragments.

Clarke, A.J. 2013 '"Actions Speak Louder": Victor Papanek and the Legacy of Design Activism.' Design and Culture 5(2): 151-168.

Cuff, D. 1992, c1991 Architecture: The story of practice, Cambridge, Mass: MIT Press.

Dunne, A. and Raby, F. 2013 Speculative everything: Design, fiction, and social dreaming, Cambridge (Mass.): MIT Press.

Ebbensgaard, C.L. 2016 Rethinking urban lighting: geographies of artificial lighting in everyday life. PhD, London, Roskilde:

Edensor, T. 2017 From light to dark: Daylight, illumination, and gloom, Minneapolis: University of Minnesota Press.

Edensor, T. and Millington, S. 2009 'Illuminations, Class Identities and the Contested Landscapes of Christmas.' Sociology 43(1): 103-121.

Entwistle, J. and Slater, D.R. under review 'The material politics of light: urban lighting and masterplanning in a municipal regeneration process.'.

Entwistle, J., Slater, D.R. and Sloane, M. 2015 'Derby' in S. Isenstadt, Dietrich Neumann and M.M. Petty (eds.) Cities of Light: Two Centuries of Urban Illumination, New York: Routledge: 159-164.

Farias, I. and Wilkie, A. (eds.). 2015 Studio Studies: Operations, Topologies \& Displacements, London: Routledge.

Gehl, J. 2011 [1980] Life between buildings: Using public space, Washington DC: Island Press.

Genus, A. and Jensen, C. 2017 'Beyond 'behaviour': The institutionalisation of practice and the case of energy-efficient lighting in Denmark.' Journal of Consumer Culture: 146954051771778.

Green, M. 2000 'Participatory Development and the Appropriation of Agency in Southern Tanzania.' Critique of Anthropology 20(1): 67-89.

Ingold, T. 2016 'Lighting up the atmosphere' in M. Bille and T.F. Sørensen (eds.) Elements of architecture: Assembling archaeology, atmosphere and the performance of building spaces, Abingdon: Rougledge: 163-176.

Isenstadt, S., Dietrich Neumann and Petty, M.M. (eds.). 2015 Cities of Light: Two Centuries of Urban Illumination, New York: Routledge.

Ivory, C. 2013 'The role of the imagined user in planning and design narratives.' Planning Theory 12(4): 425-441.

Julier, G. 2005 'Urban designscapes and the production of aesthetic consent.' Urban Studies 42(5): 869-887.

Kimbell, L. 2011 'Rethinking Design Thinking: Part I.' Design and Culture 3(3): 285-306.

Kohler, D. 2014 'The lighting master plan as an instrument for municipalities: A critical assessment of possibilities and limitations' in J. Meier, U. Hasenöhrl, K. Krause and M. Pottharst (eds.) Urban Lighting, Light Pollution and Society, New York: Routledge: 141-158.

Latour, B. 1992 'Where are the missing masses?: The sociology of a few mundane artefacts' in W.E. Bijker and J. Law (eds.) Shaping technology/building society: Studies in Sociotechnical change, Cambridge, MA: MIT Press.

Law, J. 2004 After Method: Mess in Social Science Research, Abingdon and New York: Routledge.

Law, J. and Urry, J. 2004 'Enacting the social.' Economy and Society 33(3): 390-410.

Lee, K.-W. 2014 'Feeling like a State: Design Guidelines and the Legibility of 'Urban Experience' in Singapore.' International Journal of Urban and Regional Research 38(1): 138-154. 
Lury, C. and Wakeford, N. (eds.). 2014 Inventive methods: The happening of the social, London: Routledge.

Lynch, K. 1960 [1975] The image of the city, Cambridge Mass: MIT Press.

Lynch, K. 1984 Good city form, Cambridge Mass.: MIT Press.

Major, M. 2015 'London: Light+Dark=Legibility: An Approach to Urban Lighting' in S. Isenstadt, Dietrich Neumann and M.M. Petty (eds.) Cities of Light: Two Centuries of Urban Illumination, New York: Routledge: 152-158.

Marres, N., Guggenheim, M. and Wilkie, A. (eds.). 2018 Inventing the Social, London: Mattering Press.

McQuire, S. 2005 'Immaterial Architectures: Urban Space and Electric Light.' Space and Culture 8(2): 126-140.

Narboni, R. 2004 Lighting the landscape: Art design technologies, Basel, Switzerland: Birkäuser.

Oudshoorn, N. and Pinch, T. 2003 How users matter: The co-construction of users and technologies / edited by Nelly Oudshoorn and Trevor Pinch, Cambridge, Mass., London: MIT.

Papanek, V. 1985 [1971] Design for the real world: Human ecology and social change, London: Thames and Hudson.

Petty, M.M. 2007 'Illuminating the Glass Box: Architectural lighting design and the performance of modern architecture in post-war America.' Journal of the Society of Architectural Historians 66(2): 194-21.

Petty, M.M. 2016 Cultures of Light: Electric light in the United States, 18902-1950s. PhD, Wellington, New Zealand:

Pink, S. and Leder Mackley, K. 2014 'Moving, Making and Atmosphere: Routines of Home as Sites for Mundane Improvisation.' Mobilities: 1-17.

Riles, A. 2000 The Network Inside Out, Ann Arbor: University of Michigan Press.

Rydin, Y. 2007 'Re-Examining the Role of Knowledge Within Planning Theory.' Planning Theory 6(1): 52-68.

Schivelbusch, W. 1995 [1983] Disenchanted night: The industrialization of light in the nineteenth century, Berkeley: University of California Press.

Shaw, R. 2014 'Street-Lighting in England and Wales: New Technologies and Uncertainty in the Assemblage of Street-Lighting Infrastructure.' Environment and Planning A.

Shove, E. and Spurling, N. (eds.). 2014 Sustainable practices: Social theory and climate change, London: Routledge.

Slater, D.R. 2013 New Media, Development and Globalization: Making Connections in the Global South, Cambridge: Polity Press.

Slater, D.R., Bordonaro, E. and Entwistle, J. 2018 Social Lightscapes Workshops: social research in design for lighting professionals, Ancona, Italy: iGuzzini.

Sloane, M., Slater, D.R. and Entwistle, J. 2016 Tackling Social Inequalities in Public Lighting, London:

Star, S.L. and Griesemar, J.R. 1989 'Institutional ecology, translations and boundary objects.' Social Studies of Science 19: 387-430.

Wilkie, A. and Michael, M. 2009 'Expectation and Mobilisation: Enacting Future Users.' Science, Technology \& Human Values 34(4): 502-522.

Wilkie, A., Savransky, M. and Rosengarten, M. 2017 Speculative research: The lure of possible futures, London: Routledge. 


\begin{abstract}
' The article draws on work with many collaborators, professional and academic. We particularly want to acknowledge our debt to Dr Elettra Bordonaro, lighting designer and third core member of the Configuring Light research group. The Whitecross project involved two phases, the first funded by LSE's HEIF5 funding and enabled by the support of Peabody Trust and iGuzzini; the second directly funded by Peabody. A former team member, Mona Sloane, played an important role in project concept, administration and fieldwork. The Derby project grew out of our collaboration with Speirs+Major, and particularly our work with Mark Major and Satu Streatfield, to whom we are indebted for their ongoing support; the research was supported, and funded, by Derby city council's regeneration team then lead by Pranali Pareekh. Mona Sloane participated in this research.
\end{abstract}

